\title{
Stroke Rehabilitation and Fall Incidences in Rural Areas: A Survey
}

\author{
Paras Joshi $^{1}$, Dinesh Sorani ${ }^{2}$ \\ ${ }^{1} \mathrm{PhD}$ Scholar, Saurashtra University \& Physiotherapist at PDU Government Hospital Rajkot. \\ ${ }^{2}$ Principal, Government Physiotherapy College, Jamnagar.
}

Corresponding Author: Paras Joshi

\begin{abstract}
Stroke is the leading cause of disability morbidity and mortality in the world. Stroke patients suffer from spasticity, balance issues and other higher mental issues. Stroke patients are prone to falls and fall related injuries during their recovery period. Rehabilitation for such patients may be a challenge in country like India due to their unawareness about importance of physiotherapy, economical status and unavailability of proper rehabilitation centers. Survey was done for the same.
\end{abstract}

Method: 352 patients were asked about their rehabilitation and fall incidents during their first 6 months after stroke via telephone interview.

Result: $42.61 \%$ (150) participants agreed that proper stroke rehabilitation is necessary after the incident of stroke, and only $17.05 \%$ (60) participants received the proper rehabilitation. Among Participants who did not receive rehabilitation (292), fell significantly higher than those who received the rehabilitation (60) during the first 6 months from the onset of stroke. Among all fallers $24.09 \%$ reported serious injuries which required medical attention including fractures.

Conclusion: Stroke Rehabilitation is inadequate in rural areas due to variety of reasons, which may lead to increase in number of falls and fall related injuries

Key words: Stroke, Rehabilitation, fall incidences, balance, cognition

\section{INTRODUCTION}

According to WHO, Stroke is rapidly developing clinical signs of focal (or global) disturbance of cerebral function with symptoms lasting 24 hours or longer or leading to death, with no apparent cause other than of vascular origin.

The annual stroke incidence rate was slightly higher in the rural population than in the urban hyperlipidemia population (crude incidence rate, 116/100,000 personyears for the urban population versus $119 / 100,000$ person-years for the rural population; age-standardized incidence rate, $135 / 100,000$ person-years for the urban population versus $138 / 100,000$ person-years for the rural population). It also showed that the number of smokers (men) and presence of multiple risk factors (more than 3 ) were significantly more in the rural population than in the urban population. Also the distribution of conventional stroke risk factors was remarkably similar among the urban and rural communities. However, the number of stroke patients who had imaging was significantly low in the rural population. Studies from India on cardiovascular risk factors have shown a 2 to 3 time's high prevalence of hypertension, obesity, diabetes mellitus, and smoking (in men) in urban areas compared to rural communities. ${ }^{1}$

Falls are found common among post stroke patients, stroke survivors having an estimated $14 \%$ risk of falling in the first month. ${ }^{2}$ Apart from injuries, those who all experience activity limitation, increase dependence, and fear of falling. ${ }^{3}$ These 
barriers will limit social and community participation and quality of life may be compromised. ${ }^{4}$ Overcoming these are challenging, as patients require significant cognitive and emotional adjustment to successfully adopt coping strategies. It is thus important to develop effective interventions to reduce risks of a post-stroke fall. $^{5}$

It has been observed that stroke survivors in rural areas in India are not taking adequate stroke rehabilitation. This survey may give insight about probable reasons, fall incidents after stroke among non rehabilitating stroke survivors.

\section{MATERIALS AND METHODS}

352 Stroke patients who are subacute and chronic (more than 6 months of stroke and less than 1.5 years of stroke) were selected for the telephonic interview from the rural areas surrounding of Rajkot. Telephonic interview have been done for them retrospective (participants were asked to answer the questions about their 1st month post stroke to 6 months post stroke)

Participants were selected on the basis of inclusion and exclusion criteria as mentioned below.

\section{Inclusion criteria}

- Age above 40 years

- With ability to walk at least 8 meter (with assistive device if required)

\section{Exclusion criteria}

- Major musculoskeletal problems

- Neurological disorder in addition to stroke.

- More than 1 attack of stroke

\section{Design of survey}

Survey was designed to gain the information about the following things among stroke patients who are living in rural areas.

- Awareness about rehabilitation following stroke

- Availability of Rehabilitation center in nearby area

- Fall incidents after stroke.

- Type of activity during the incident of fall/s

\section{Following questions have been asked to} participants:

- Do you feel stroke rehabilitation is necessary for 6-8 months after the onset of stroke, even if you are walking by your own or with an assistive device?

- Is there a proper rehabilitation set up in your nearby area (upto $20 \mathrm{kms}$ )?

- Did you receive regular rehabilitation (min 3 days a week upto 4 months from onset of stroke) at home or at a rehabilitation center by a physiotherapist?

- If yes, Did you receive Balance training in your rehabilitation program?

- Did you receive Cognitive training in your rehabilitation program?

- Were you using any assistive device for walking during the first 6 months?

- Have you experienced any fall incidents during the first 6 months?

- If yes, how many?

- If yes, did you had any complications which required medical attention?

- Describe the activity you were doing during your fall incidences (for each fall)

\section{Statistical analysis}

Participant's data were converted in percentage. Chi square test was used to compare the number of falls in between the group.

\section{RESULTS}

Table: 1. Result summary

\begin{tabular}{|l|l|l|}
\hline Number of participants (352) & Male 222 $(\mathbf{6 3 . 0 7 \%})$ & Female 130 $(\mathbf{3 6 . 9 3 \% )}$ \\
\hline Participants view on receiving proper stroke rehabilitation after stroke & $\begin{array}{l}\text { Yes it is necessary } 150 \\
(42.61 \%)\end{array}$ & $\begin{array}{l}\text { Not necessary/ not sure 202 } \\
(57.39 \%)\end{array}$ \\
\hline Participants who received/ not received Rehabilitation during first 6 months & Received 60 (17.05\%) & Not Received 292 (82.95\%) \\
\hline
\end{tabular}




\begin{tabular}{|c|c|c|}
\hline \multicolumn{3}{|c|}{ Table 1 Continued... } \\
\hline Reasons for not taking Rehabilitation (292) & \multicolumn{2}{|c|}{$\begin{array}{l}\text { Lack of awareness } 34.59 \%(101) \text {, } \\
\text { Financial problems } 41.09 \%(120) \text {, } \\
\text { Unavailability of rehabilitation center in nearby area } \\
24.32 \%(71) \text {. }\end{array}$} \\
\hline 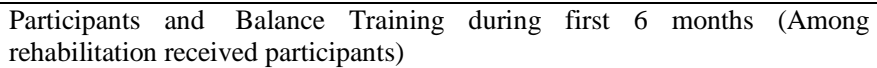 & Received $20(33.33 \%)$ & Not Received $40(66.66 \%)$ \\
\hline $\begin{array}{l}\text { Participants and Cognitive Training during first } 6 \text { months (Among } \\
\text { rehabilitation received participants) }\end{array}$ & Received $05(8.33 \%)$ & Not Received 55 (91.67\%) \\
\hline Participants and assistive device for ambulation & Used $198(56.25 \%)$ & Did not use $154(43.75 \%)$ \\
\hline Fall incidents among non rehabilitation people during first 6 months (292) & \multicolumn{2}{|c|}{$\begin{array}{l}\text { Did not fall } 149(51 \%) \\
1 \text { Fall } 105(36 \%) \\
\text { More than } 1 \text { Fall } 38(13 \%)\end{array}$} \\
\hline Fall incidents among rehabilitation people during first 6 months (60) & \multicolumn{2}{|c|}{$\begin{array}{l}\text { Did not fall } 37(61.67 \%) \\
1 \text { fall } 18 \quad(30 \%) \\
\text { More than } 1 \text { fall } 5(8.33 \%)\end{array}$} \\
\hline Serious injuries ( like fractures) reported among fallers (166) & $\begin{array}{l}\text { Yes reported } \\
40(24.09 \%)\end{array}$ & $\begin{array}{l}\text { Not reported } \\
126(75.91 \%)\end{array}$ \\
\hline Activities participants were attempting while falling (166) & \multicolumn{2}{|c|}{$\begin{array}{l}\text { Transfer activities } 60(36.14 \%) \\
\text { Crossing over obstacles } 37(22.29 \%) \\
\text { Slippery surfaces like bathroom } 43(25.90 \%) \\
\text { Others } 26(15.66 \%)\end{array}$} \\
\hline
\end{tabular}

Table 2. Chi Square test analysis

\begin{tabular}{|l|l|l|l|l|}
\hline & $\begin{array}{l}\text { Non Rehab Group } \\
\text { N=(292) }\end{array}$ & $\begin{array}{l}\text { Rehab Group } \\
\mathbf{N}=(\mathbf{6 0})\end{array}$ & Chi Square value with df 1 & Level of significance \\
\hline Did not fall & $149 / 292(51 \%)$ & $37 / 60(61.67 \%)$ & 2.254 & $\mathrm{P}=0.1332(\mathrm{P}<0.5)$ \\
\hline 1 fall & $105 / 292(36 \%)$ & $18 / 60(30 \%)$ & 0.775 & $\mathrm{P}=0.3786(\mathrm{P}<0.5)$ \\
\hline More than 1 Fall & $38 / 292(13 \%)$ & $5 / 60(8.33 \%)$ & 1.104 & $\mathrm{P}=0.3140(\mathrm{P}<0.5)$ \\
\hline
\end{tabular}

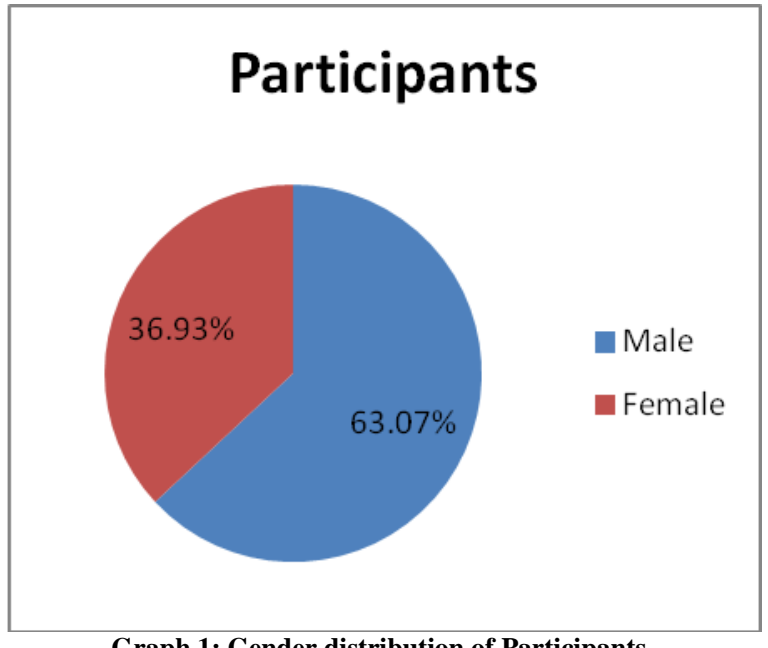

Graph 1: Gender distribution of Participants

\section{Fall incidents among participants}

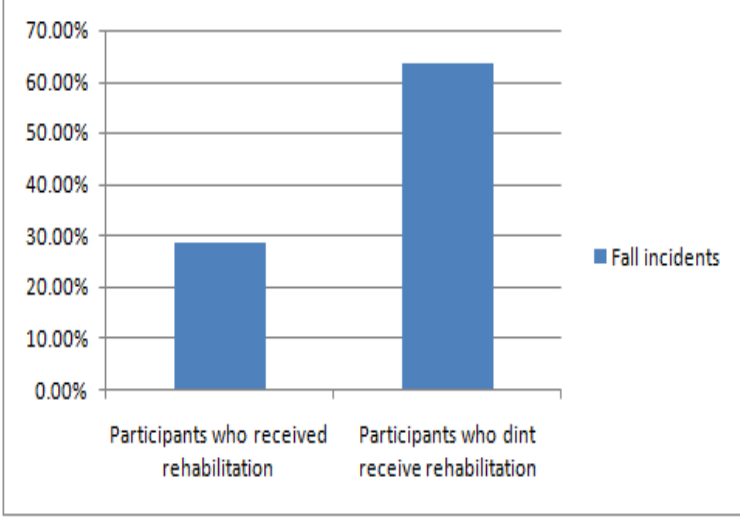

Graph 2: Fall incidents among participants who received Rehabilitation and who did not receive rehabilitation

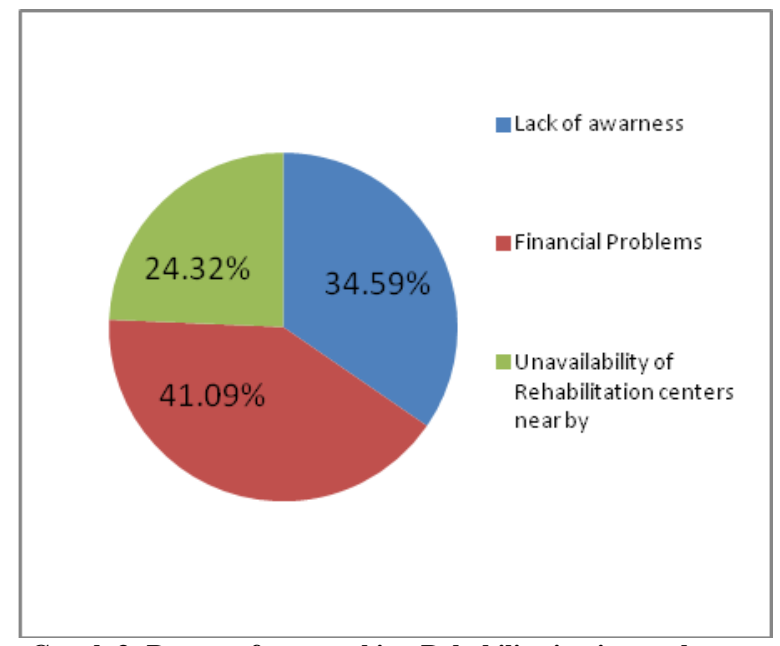

Graph 3: Reasons for not taking Rehabilitation in rural areas 


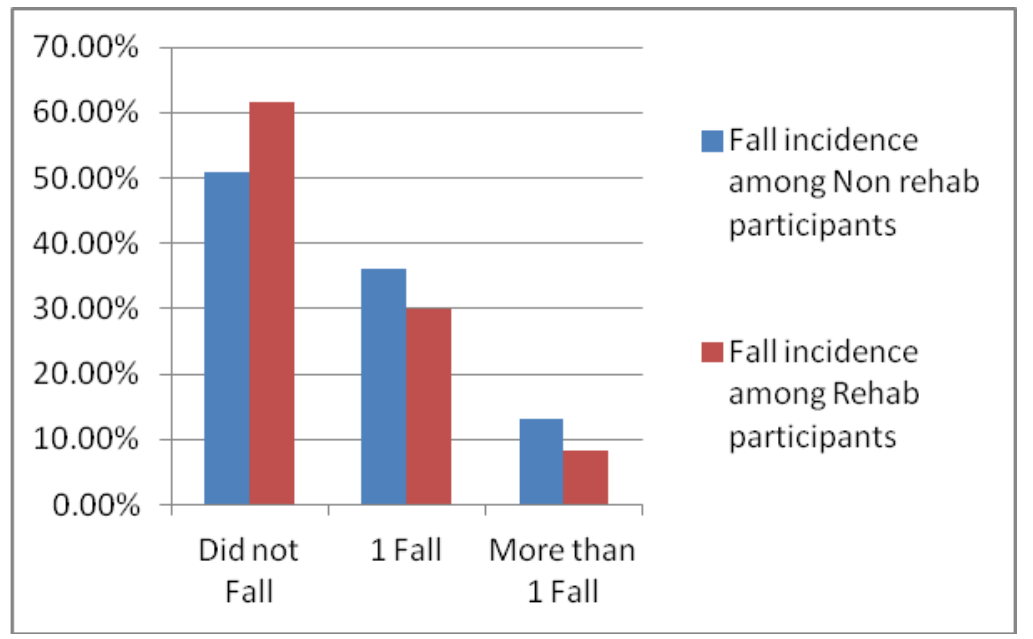

Graph 4: Fall incidents among participants who took rehabilitation and who did not took rehabilitation

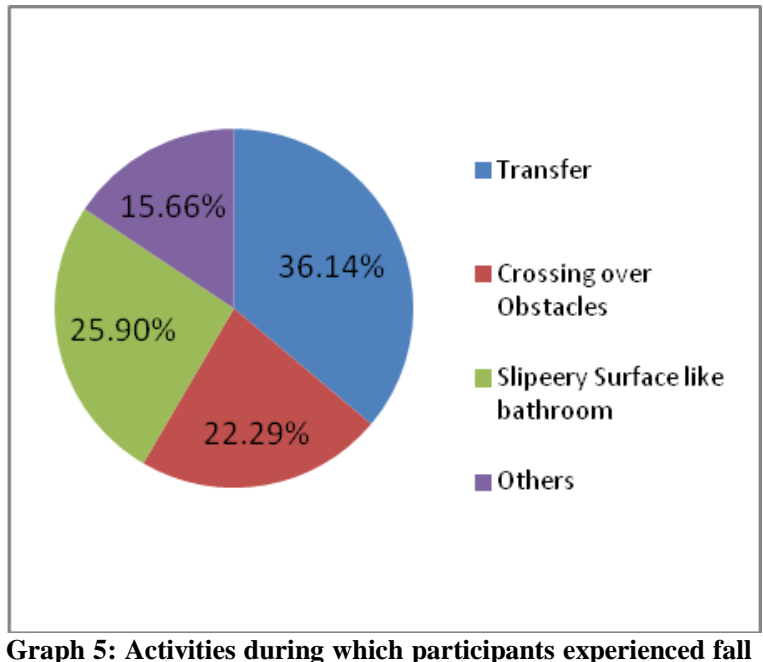
incidents

Total 352 participants took part in the survey via telephonic interview. $63.07 \%$ (222) were male participants, while $36.93 \%$ (130) were female participants.

$42.61 \%(150)$ participants agreed that proper stroke rehabilitation is necessary after the incident of stroke, while $57.39 \%$ (202) participants were not sure or did not agree about the importance of rehabilitation after stroke.

Out of all participants only $17.05 \%$ (60) participants received the proper rehabilitation (Minimum 3 days/ week upto minimum of 4 months/ 48 days in first 6 months), while $82.95 \%$ (292)did not receive the rehabilitation program.

Reasons for not taking rehabilitation were lack of awareness $34.59 \%$ (101), financial problems $41.09 \%$ (120), no nearby rehabilitation center $24.32 \%$ (71). Among patients who received Rehabilitation
(60), 66.66\% (37) did not receive balance training and $91.67 \%$ (55) did not receive cognitive training. Among Participants who did not receive rehabilitation (292), 51\% (149) patients did not fall at al, 36\% (105) patients fell once and $13 \%$ (38) patients fell more than once during the first 6 months from the onset of stroke. Among Participants who received rehabilitation (60), 61.67\% (37) patients did not fall at all, $30 \%$ (23) patients fell once and $8.33 \%$ (5) patients fell more than once during the first 6 months from the onset of stroke.

Chi square test was used to compare the number of falls between the groups. There was a statistical significant difference in number of falls between those who took rehabilitation and those who did not take rehabilitation.

Among all fallers $24.09 \%$ reported serious injuries which required medical attention including fractures. Among all fallers $36.14 \%$ fell during transfer activity, $22.29 \%$ fell during crossing an obstacle, $25.90 \%$ fell due to slippery surfaces while $15.66 \%$ reported other reasons.

\section{DISCUSSION}

The aim of this survey was to check that about how many \% of stroke survivors received adequate rehabilitation. What was the primary reason for not taking the rehabilitation? Effect of rehabilitation on number fall incidents in first 6 months.

It has been observed that in rural areas, stroke survivors do not take adequate 
rehabilitation due to multiple personal and availability of related infrastructure related reasons. Post stroke patients are prone to falls and fall related injuries. Results show that most of the stroke survivors are skipping the adequate rehabilitation. And such patients have tendency to fall more and get more fall related injuries compare to patients who received stroke rehabilitation. Transfer activities, crossing over obstacles and slippery surfaces are three primary reasons for falls. Among all fall incidents about one quarter reported serious injuries which requires due medical attention including fracture

The poor people are increasingly affected by stroke, because of both the changing population exposures to risk factors and, most tragically, not being able to afford the high cost for stroke care. Majority of stroke survivors continue to live with disabilities, and the costs of on-going rehabilitation and long term-care are largely undertaken by family members, which impoverish their families. ${ }^{6,7}$ our study also supports their statement that financial problems remain number one for taking the adequate rehabilitations.

Major risk factors for falls among community stroke survivors have been identified and in descending order of risk are: impaired mobility, reduced balance, use of psychotropic medications, disability in self-care, depression, cognitive impairment and a history of falls. ${ }^{8}$ if such risk factors are modified through proper rehabilitation fall incidents can be prevented at large. Possibly this is the reason we see significant difference in fall incidences in our study between those who received rehabilitation and those who dint receive rehabilitation. However, among those who received rehabilitation among patients, 66.66\% (40) did not receive balance training and $91.67 \%$ (55) did not receive cognitive training. Perhaps being important risk factors were not modified even in rehabilitation groups may leads to more number of falls.

\section{Limitations of study}

Types of stroke and comorbid factors were not asked as there were chances of false information from the participants. Survey type was subjective hence information regarding past history about any other neurological disorder, number of falls may not be accurate.

We were not able to exclude Stroke participants with cerebellar lesions and perceptual disorders during telephonic interviews which can affect the study outcome.

Factors like age hemiosteoporosis related to falls were not included in the study.

\section{Further recommendations}

Appropriate solution may be found by applying routing home exercise program with regular routing monthly or weekly follow up. Such protocol may be made and checked.

Further large cross sectional studies are recommended in rural areas of India to get more accurate data.

\section{CONCLUSION}

Most of the post stroke patients do not think that post stroke rehabilitation is necessary. Only about $17.05 \%$ patients (post stroke) are receiving proper rehabilitation in rural areas. Financial reasons are the primary reason for not taking proper rehabilitation followed by the lack of awareness and unavailability of rehabilitation centers in nearby areas. Though balance and cognitive training is an integral part of rehabilitation it is usually ignored during the first 4-6 months in the rehabilitation center.

Fall incidents are more common in patients who don't take rehabilitation compared to who take rehabilitation. About one quarter of patients may report serious injuries after fall incidents post stroke in the first 6 months. Transfer activity is more vulnerable for stroke patients in terms of fall and fall related injuries followed by crossing 
an obstacle and walking over slippery surfaces.

People should be made aware about the importance of stroke rehabilitation. They should be further aware that they are more likely to fall and get fall related fatal injuries compared to healthy individuals of same age and gender. More rehabilitation centers can be generated in rural areas. Balance and cognitive training can be added in a routine rehabilitation program. To prevent fall incidents proper home modification can be done like removing obstacles, facilitation transfer activity and modification in surface area of washroom/ bathrooms.

\section{ACKNOWLEDGMENT}

I am thankful to various physiotherapy centers in around Rajkot to provide me data about stroke survivors. I am thankful to Dr Vidhi Talati and Dr Krupa Mehta for assisting me.

\section{Conflict of Interest: None}

\section{Source of Funding: None}

\section{Ethical Approval: Approved}

\section{REFERENCES}

1. Jeyaraj Durai Pandian, Paulin Sudhan. Stroke epidemiology and stroke care services in India. J Stroke. 2013 Sep;15(3): 128-34.
2. Wagner LM, Phillips VL, Hunsaker AE, Forducey PG. Falls among communityresiding stroke survivors following inpatient rehabilitation: a descriptive analysis of longitudinal data. BMC Geriatr. 2009; 9(1):46.

3. Schmid AA, Rittman M. Consequences of poststroke falls: activity limitation, increased dependence, and the development of fear of falling. Am J Occup Ther. 2009;63(3):310-6.

4. Batchelor FA, Mackintosh SF, Said CM, Hill KD. Falls after Stroke. Int J Stroke [Internet]. 2012;7(6):482-90. Available from. https://doi.org/10.1111/j.17474949.2012.00796.x.

5. Walsh M, Galvin R, Horgan NF. Fallrelated experiences of stroke survivors: a meta-ethnography. Disabil Rehabil. 2017;39(7):631-40.

6. Bonita R, Beaglehole R. Stroke prevention in poor countries. Time for action. Stroke. 2007;38:2871-2872.

7. Pandian JD, Srikanth V, Read SJ, Thrift AG. Poverty and stroke in India. A time to act. Stroke. 2007;38:3063-3069.

8. $\mathrm{Xu} \mathrm{T}$, Clemson L, O'Loughlin K, Lannin NA, Dean C, Koh G. Risk factors for falls in community stroke survivors: a systematic review and meta-analysis. Arch Phys med Rehabil. 2018;99(3):563-573.e5.

How to cite this article: Joshi P, Sorani D. Stroke rehabilitation and fall incidences in rural areas: a survey. Int J Health Sci Res. 2021; 11(10): 239-244. DOI: https://doi.org/10.52403 /ijhsr.20211031 